\title{
Sexual Experience, Suicidal Behaviors and Depression Association, and Its Tendency to Lead to Smoking and Alcohol Consumption among Korean Adolescents
}

\author{
Baby Doll Bana1 ${ }^{1}$, Jinsoo Jason $\mathrm{Kim}^{2 *}$, Jerre Mae Tamanal ${ }^{3}$, and Sun Hee Kim² \\ ${ }^{1}$ Doctorate Student, Addiction Science Department \\ Sahmyook University (Seoul, Korea) \\ ${ }^{2}$ Assistant Professor, Addiction Science Department, \\ Sahmyook University, Seoul, Korea \\ ${ }^{3}$ Research Assistant, Addiction Science Department, \\ Sahmyook University, (Seoul, Korea) \\ *Corresponding author's email: kimjj [AT] syu.ac.kr
}

\begin{abstract}
In numerous published findings, the cohesion was they have treated sexual experience, suicidal behaviors and depression, as the outcome variables and regard substance use as the core factors. In this study, we aim to do the opposite. We seek to make sense of the linkage by inversing the analytical direction. We intend to examine the association and the likelihood, and observe the levels to which sexual experience, suicidal behaviors, and depression may play a part in the odds of smoking and alcohol drinking among middle school and high school Korean students. The data obtained were cross-sectional from the 2019 Korean Youth Risk Behavior Web-Based Survey, participated by 57, 303 Korean adolescents. Among which are male 52.1\%, female 47.9\%, ages 15 below $59.2 \%$ and 15 above 40.4\%. This study utilized descriptive, Chi-square, and logistic regression analyses. Our basic findings signified that sexual experience and mental health problems doubled the odds of motivation. Chi-square analyses asserted that the association was statistically significant. All variables were notably correlated to substance use at 0.01 level, that is, when sexual experience, suicidal behaviors, and depression tend to increase, there was a high risk of using substances. The results for logistic regression on alcohol drinking, the $-2 L L$ statistic is 73157.25 , the Cox \& Snell $R 2$ is 0.057 , and Nagelkerke $R 2$ is 0.078 having the df of 1, with the p value of 0.0001 , and the $-2 L L$ statistic is 39022.46, the Cox \& Snell $R 2$ is 0.064, and Nagelkerke $R 2$ is 0.122 having the df of 1 , with the $p$ value of 0.000 for smoking, predicted the maximum likelihood and considerably identified as positive significant indicators in the onset of substance initiation. This study also found that sexual experience had remained robustly substantial with the odds of smoking and drinking, that is, participants with higher sexual experience had the strongest likelihood of substance use motivation. Our overall results contribute to the debate by treating sexual experience, suicidal behaviors, and depression as precedent significant risk factors for developing substance use behaviors among Korean adolescents. For efficient and effective management of sexual experience, suicidal behaviors and depression on teenagers, findings underscore the need for early detection on adolescents at risk. A comprehensive prevention and protective efforts is required along with continuous parental guidance. Intervention programs with coping skills to handle emotional and behavioral problems is essential to help reduce the probability of an increased risk factors and subsequently lessen the threat for developing cigarette smoking and alcohol drinking behaviors among teenagers. School-based programs that can create synergy by embedding teenagers in an academic environment that is equally supportive, beneficial and can help promote a positive mindset is recommended.
\end{abstract}

Keywords - alcohol consumption, depression, Korean adolescents, sexual experience, smoking initiation, suicidal behaviors

\section{INTRODUCTION}

The use of tobacco, alcohol, and prohibited drug use remains persistently high in many countries, despite several years of significant concern, copious efforts for preventative programs, inadequate resource expenditure on mass media, school curricula, and scholastic resource production [1]. Substance use is highest during adolescence [2]. Unhealthful behaviors such as drinking and smoking often begin during this stage, affect health, and result in adulthood disorders [3]. Substance use is, directly and indirectly, accountable for 11.8 million deaths every year. It is responsible for one in five deaths worldwide, and only 1 in 7 users receive treatment out of the 35 million people who 
suffer from substance use globally [4,5]. Smoking and drinking have become one of the most critical public health concerns among the youth population worldwide [6-8].

Substance use in depression is highly prevalent, and its frequency has not changed over decades [9]. Individuals diagnosed with substance use have 3 to 4 times depression prevalence. In most clinical practice, it has been observed and documented that comorbidity of substance use and depression among patients suffering from dual diagnoses has been an essential matter to be seriously considered. Reciprocation in this comorbidity has been observed in all pharmacological types of addictive drugs, including nicotine and alcohol [10]. Substance use is prevalently cooccurring with depression and can work bi-directionally or vice versa [11]. Literature suggests that depression is more likely to develop when a higher alcohol level is consumed [12]. Retrospective studies signify early-onset smoking projects a higher risk for depression and more chronic depressive symptoms [13]. Other issues may develop when both exist together, especially among adolescents at risk of experiencing poor outcomes [14].

Positive association between problems with substance use and depression levels in adolescents might cause a higher risk for a suicidal attempt [15].

Studies suggested a strong association between substance use and severe risk for suicidal behaviors, especially for patients aged 15-30 years old suffering from psychiatric disorders [16]. In adolescents, the co-occurrence of alcohol, tobacco, and suicidal ideation had a statistically significant relationship. Health-related behaviors such as alcohol drinking and smoking are associated with suicidal behavior [17-18]. Alcohol dependence increases the risk of suicide, death risk of suicide attempt, and risk of suicidal ideation by 2.59 percent [19]. Smoking appears to be the best predictor of sexually risky behavior in male and female adolescents [20-21].

Alcohol drinking and smoking cigarettes work as a short-range mating strategy. It increases the risk of adolescent sexual urge, especially among high school students engaging in sexual intercourse, provided that cigarette and alcohol use are still considered masculine traits, especially among men [22-23]. Researchers have also discovered that as substance use increased in frequency, the probability of sex and the number of sexual partners also increased. Substance use has more substantial effects on sexual behavior among the female population, especially individuals of Hispanic, Asian, and Caucasian origin, and among older youth. A study with a sample of 60,000 young adults implied a relationship between cigarette smoking and the onset of sexual activity [24-26]. A vast spectrum of studies highlight and document the proximal role of smoking and alcohol consumption as initiates to suicidal behaviors, depression, and sexual experience.

In South Korea, more than 59, 000 children 10-14 years old continuously consume cigarettes each day. The daily number of users are 9-24-year-olds had reached 8.99 million, representing $17.4 \%$ percent of the country's entire population. [27] Data from Statista's Key Market Indicators (KMI) has also projected smoking prevalence in South Korea to reach 20. 2\% (15 years older) by 2025. Approximately $9.1 \%$ of South Koreans aged 9-17 have consumed alcohol. The rate was significantly high among male respondents, with an estimated $13.4 \%$. Koreans consumed alcohol on average 8.8 days per month [28].

Adolescent suicide is also the most serious and almost permanent psychological health problem. Suicide has been consistently the second -most common cause of death in the younger population ranging from 10-19 years old. There was a remarkable increase from 5.3 persons per 100,000 in 2001 , to $35 \%$ to 7.2 persons per 100 , 000 in 2014 [29]. Moreover, the most common cause of death in Korean adolescents is suicide [30]; In fact, the rate of suicide attempts among Korean adolescents has continuously increased; in 2016, the suicide rate among Korean adolescents aged 12 up to 18 years was 7.9 per 100,000, which was twice as that in 20015. [31] In 2016, suicide became the number 1 cause of death among the youth population in South Korea, and the rate has been rising over the years [32]. Suicide continuous to be extremely and the most critical psychological problem in the country.

Risk factors cover mental and behavioral aspects encompassing depression, smoking, alcohol consumption, sexual activity, and high stress, however, a psychiatric disorder such as depression was the primary cause of death of the $90 \%$ of Koreans who committed suicide in 2016 [33]. The proportion of Korean adolescents who experienced depression was decreased to $27.1 \%$ in 2018 from $41.3 \%$ in 2007, a reduction of 14.2 percentage points (\%p). According to 2018 data, the proportion was $33.6 \%$ for schoolgirls, and $21.1 \%$ for schoolboys, with a difference of 1 . 6 folds higher in girls. High school students $28.7 \%$ displayed a seemingly higher proportion than middle school students $25.2 \%$ [34].

In Korea, there is a significant increase in the number of young people who smoke, consume alcohol, and are sexually active. It is alarming the average age group is even younger in 2015 (13.2-year-olds) compared with (13.8year-olds) in 2009 [35]. The number of young people with sexual experiences has double increased from 2 to 4 times as they also reported the use of prohibited drugs, alcohol consumption, and smoking cigarettes. There are less than $30 \%$ of the respondents admitted to always using contraception while nearly half don't use it [36]. 
Research examining these factors among adolescents continues to accumulate. However, there is almost no research conducted in reversal to these studies. Minimal records reported, in which frequency has also been poorly documented, and a short period or small samples are often used. This puts limitations on the research's ability to examine thoroughly a subject that has been essentially overlooked in medical research.

Therefore, this study intends to investigate the opposite direction. We aim to measure the association and the likelihood of sexual experience and mental health problems on smoking and drinking motivation among middle and high school Korean students. The current exploration is designed to evaluate these factors' relationships in an integrated and concrete manner by combining the variables in one model.

\section{METHOD}

\subsection{Data}

We used the data from the 2019 Korean Youth Risk Behavior Web-Based Survey (KYRBS). The KYRBS is a statistical government-approve survey conducted annually since 2005 by the Korea Centers for Disease Control and Prevention to monitor health-related risk behaviors among Korean adolescents. A stratified multistage cluster sampling design was used to obtain a nationally representative sample of middle- and high-school students. The survey was completed anonymously and received a very high participation rate - the participants of this research had a very high response rating and almost had no missing data. Based on the released data by KYRBS 2019, there is 57303 participants who were sampled using the multistage clustered probability design within the whole country.

\subsection{Measurement}

\subsubsection{Socio-demographic}

Socio-demographic variables included age, gender, and student's education level (Middle and High School). Perceived Socioeconomic Status was assessed by a 5-point Likert scale (high, middle-high, middle, middle-low, and low). Living Conditions were classified by those who live with family, relatives, boarding with friends, dormitory, and welfare centers.

\subsubsection{Suicidal Behaviors}

Suicidal thoughts, plans, and attempts were used as factors for suicidal behaviors and were classified by responding with "yes" and "no" to a question asked whether each respondent had seriously considered suicide and had set up suicidal schemes during a year.

\subsubsection{Depression}

Depression experience was also categorized by responding with a "yes" or "no" as to whether participants had felt desperate or sad enough to have their daily lives affected for two weeks.

\subsubsection{Substance use (smoking and drinking)}

Smoking and drinking experience was classified as substance use behavior. Lifetime smoking and drinking experience were assessed by responses with a "yes" or "no" to each question about smoking and drinking experience. Questions asked: "Have you ever smoked at least one cigarette daily in the last 30 days?" and "Have you ever consumed alcohol in the last 30 days?

\subsubsection{Sexual Experience} had sex?"

Similarly, the sexual experience was also analyzed by the response "yes" or "no" to the question "have you ever

\subsection{Statistical Analysis}

The data from the KYRBS is multifaceted sample survey data, and it was analyzed by employing cluster, weight, and stratification methods of statistical analysis. All the analyses were performed using SPSS version 24 for Windows (IBM, 2021). After presenting descriptive statistics including means, standard deviation, frequency distribution, and percentage of the respondents, a Chi-square test with the statistical level set $p$-value $<0.05$ was performed to analyze the association of the study variables relating to sexual experience, mental health problems such as depression, suicidal behaviors (thoughts, plans, attempts), on smoking and alcohol consumption. Logistic regression was utilized to determine the consumption of substances (smoking and alcohol drinking). 


\section{RESULT}

\section{Frequency Distribution of the Respondents}

Descriptive statistics of socio-demographic variables exhibited 57303 participants were analyzed for this study (See Table 1). The analytic sample consisted of 29841 (52.1\%) males and $27462(47.9 \%)$ females. Age was categorized into two groups, under $15(N=33,908,59.2 \%)$ and over $15(N=23,161,(40.4 \%)$, of the middle school and high school. The highest percentage among the socioeconomic status groups comes from the middle-income group, i.e., 27457 (47.9\%), where their majority live with their families, i.e., 54267 (94.7\%).

Table 1. Frequency Distribution of the Respondents $(N=57303)$

\begin{tabular}{lll}
\hline Variables & Frequency & Percent (\%) \\
\hline Gender & & \\
Male & 29841 & 52.1 \\
Female & 27462 & 47.9 \\
Age & & \\
Under 15 & 33908 & 59.2 \\
Over 15 & 23161 & 40.4 \\
& & \\
Education & & \\
Middle School & 29384 & 51.3 \\
High School & 27919 & 48.8 \\
& & \\
Socio-Economic Status & & \\
High & 6379 & 11.1 \\
Middle High & 16126 & 28.1 \\
Middle & 27457 & 47.9 \\
Middle Low & 6042 & 10.5 \\
Low & 1299 & 2.3 \\
Living Conditions & & \\
Family & & \\
Relatives & 54267 & 94.7 \\
Boarding with Friends & 332 & 0.6 \\
Dormitory & 347 & 0.6 \\
Welfare Centers & 2126 & 3.7 \\
\hline
\end{tabular}

Results from Chi-square analyses for smoking were observed (see Table 2). The participants were identified as smokers $(N=7076,12.3 \%)$ and non-smokers $(N=50227,87.7 \%)$. Evidence confirmed the strength of the association was statistically significant in all the study variables at $p$ value $<0.05$. Smoking was the highest dependent from sexual experience $\left(\chi^{2}=5005.66, \mathrm{p}=.000\right)$, followed by depression $\left(\chi^{2}=652.26, p=.000\right)$. As for suicidal behaviors, there is a slight difference between suicidal attempts $\left(\chi^{2}=476.52, p=.000\right)$ and suicidal thoughts $\left(\chi^{2}=475.46, p=.000\right)$, compared to suicidal plans $\left(\chi^{2}=371.32, p=.000\right)$.

Table 2. The Correlation between mental health problems, sexual experience and smoking

\begin{tabular}{|c|c|c|c|c|c|}
\hline & \multicolumn{2}{|c|}{$\begin{array}{l}\text { Smoking (Yes) } \\
N=7076(12.3 \%)\end{array}$} & \multicolumn{2}{|c|}{$\begin{array}{l}\text { Smoking (No) } \\
N=50227(87.7 \%)\end{array}$} & \multirow[t]{2}{*}{$\chi^{2}$} \\
\hline & $n$ & $\%$ & $n$ & $\%$ & \\
\hline Depression & 4194 & 10.2 & 37081 & 89.8 & $652.26^{*}$ \\
\hline \multicolumn{6}{|l|}{ Suicidal Behaviors } \\
\hline Suicidal Thoughts & 5571 & 11.2 & 44234 & 88.8 & $475.46 *$ \\
\hline Suicidal Plans & 6493 & 11.8 & 48504 & 88.2 & $371.32 *$ \\
\hline Suicidal Attempts & 6568 & 11.8 & 49004 & 88.2 & $476.52 *$ \\
\hline Sexual Experience & 5376 & 10 & 48645 & 90 & $5005.66^{*}$ \\
\hline
\end{tabular}


In table 3, results from Chi-square analysis for alcohol were measured, and results were noted. The participants were identified as alcohol drinkers $(N=22240,38.8 \%)$ and non-alcohol drinkers $(N=35063,61.2 \%)$. Substantial scores established that there is a strong, statistically significant relationship among the study variables at $p$ value $<0.05$. Alcohol drinking was the highest dependent from sexual experience $\left(\chi^{2}=2262.02, p=.000\right)$, followed by depression $\left(\chi^{2}=\right.$ $1200.65, p=.000)$. As for suicidal behaviors, suicidal thoughts got the highest association $\left(\chi^{2}=685.4, p=.000\right)$, then suicidal plans $\left(\chi^{2}=360.04, p=.000\right)$, and suicidal attempts $\left(\chi^{2}=354.96, p=.000\right)$. Overall results for Tables $(2$ and 3$)$ suggest that mental health problems seemingly have influence on substance use consumption. Result's best findings highlight sexual experience as the highest association. Increased sexual activity is indicative of increased substance use.

Table 3. The Correlation between mental health problems, sexual experience and alcohol

\begin{tabular}{|c|c|c|c|c|c|}
\hline & \multicolumn{2}{|c|}{ Alcohol Consumption (Yes) } & \multicolumn{2}{|c|}{ Alcohol Consumption (No) } & \multirow{2}{*}{$\chi^{2}$} \\
\hline & $n$ & $\%$ & $n$ & $\%$ & \\
\hline Depression & 14205 & 34.4 & 2707 & 65.6 & $1200.65 *$ \\
\hline \multicolumn{6}{|l|}{ Suicidal Behaviors } \\
\hline Suicidal Thoughts & 18300 & 36.7 & 31505 & 63.3 & $685.4^{*}$ \\
\hline Suicidal Plans & 20910 & 38 & 34087 & 62 & $360.04 *$ \\
\hline Suicidal Attempts & 21192 & 38.1 & 34380 & 61.9 & $354.96 *$ \\
\hline Sexual Experience & 19677 & 36.4 & 34344 & 63.6 & $2262.02 *$ \\
\hline
\end{tabular}

$* p$ value $<0.05$

In tables 4 and 5, logistic regression was performed to explore the value of the likelihood in depression, suicidal behaviors, and sexual experience to alcohol consumption. All the subscales in (table 4) were analyzed and interpreted. In this result, the $-2 \mathrm{LL}$ statistic is 73157.25 , the Cox \& Snell $\mathrm{R}^{2}$ is 0.057 , and Nagelkerke $\mathrm{R}^{2}$ is 0.078 having the $d f$ of 1 indicating maximum probability in the initiation of alcohol consumption. Results demonstrated that all dependent variables on sexual experience $(\mathrm{OR}=C I=5.717-6.771, p=0.000)$, suicidal attempts $(\mathrm{OR}=2.489, C I=2.257-2.745, p=$ 0 .007), suicidal plans ( $\mathrm{OR}=2.221, C I=2.042-2.417, p=0.000)$, depression $(\mathrm{OR}=1.916, C I=1.846-1.988, p=$ $0.000)$, suicidal thoughts $(\mathrm{OR}=1.906, C I=1.816-2.002, p=0.000)$, have positive significant possibility to initiate alcohol drinking.

Table 4. Logistic regression analysis on depression, suicidal behaviors, and sexual experience to alcohol consumption

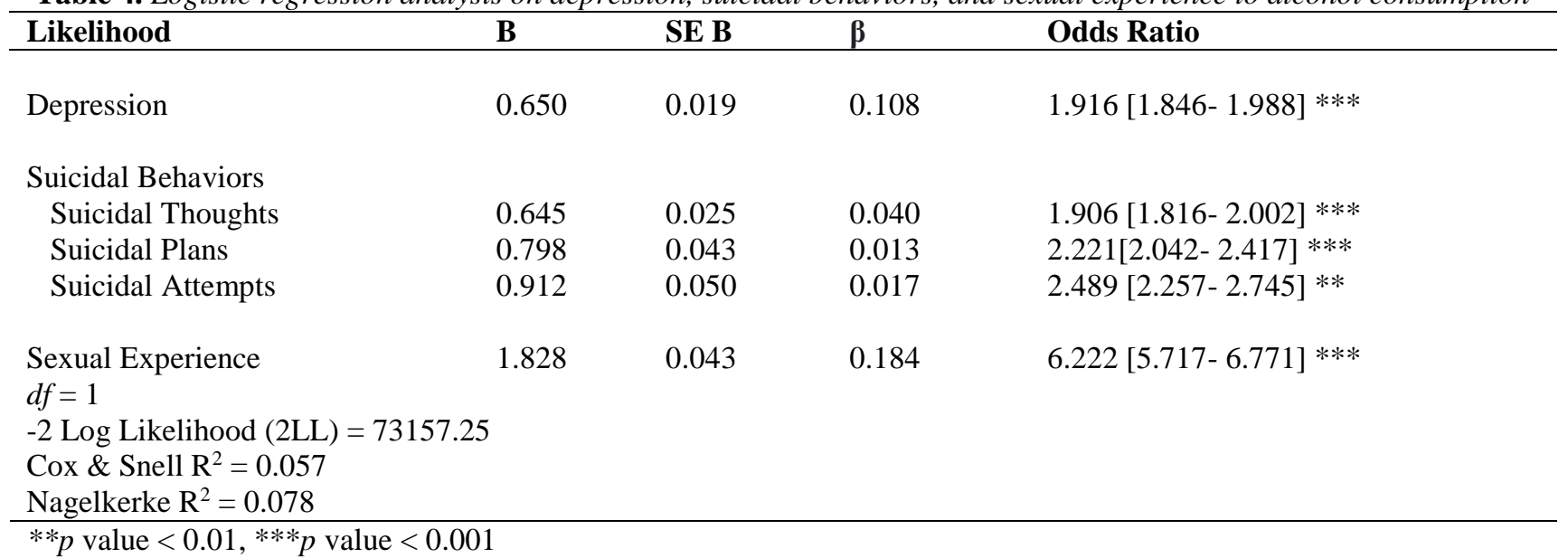

Similar outcome is also shown in smoking (see Table 5). All the results showed a positive impact and strong likelihood to smoke. the -2LL statistic is 39022.46 , the Cox \& Snell $\mathrm{R}^{2}$ is 0.064 , and Nagelkerke $\mathrm{R}^{2}$ is 0.122 having the $d f$ of 1 signifying higher probability in the initiation of smoking. Results revealed that all dependent variables on depression $(\mathrm{OR}=1.938, \mathrm{CI}=1.841-2.041, p=0.000)$, suicidal thoughts $(\mathrm{OR}=1.994, C I=1.841-2.041, p=0.000)$, suicidal plans $(\mathrm{OR}=2.528, C I=2.293-2.786, p=0.002)$, suicidal attempts $(\mathrm{OR}=3.099, C I=2.786-3.448, p=0.000)$, and sexual experience $(\mathrm{OR}=9.723, C I=9.030-10.471, p=0.000)$ have positive significant probability to initiate smoking. 
Among all the study variables in tables 4 and 5, sexual experience has remained robustly significant with the odds of smoking and drinking, which means that participants with higher sexual experience had the most substantial likelihood of substance use motivation compared to non-drinkers and non-smokers. The overall results indicate that mental health problems and sexual experience double the odds of motivation.

Table 5. Logistic regression analysis on depression, suicidal behaviors, and sexual experience to smoking

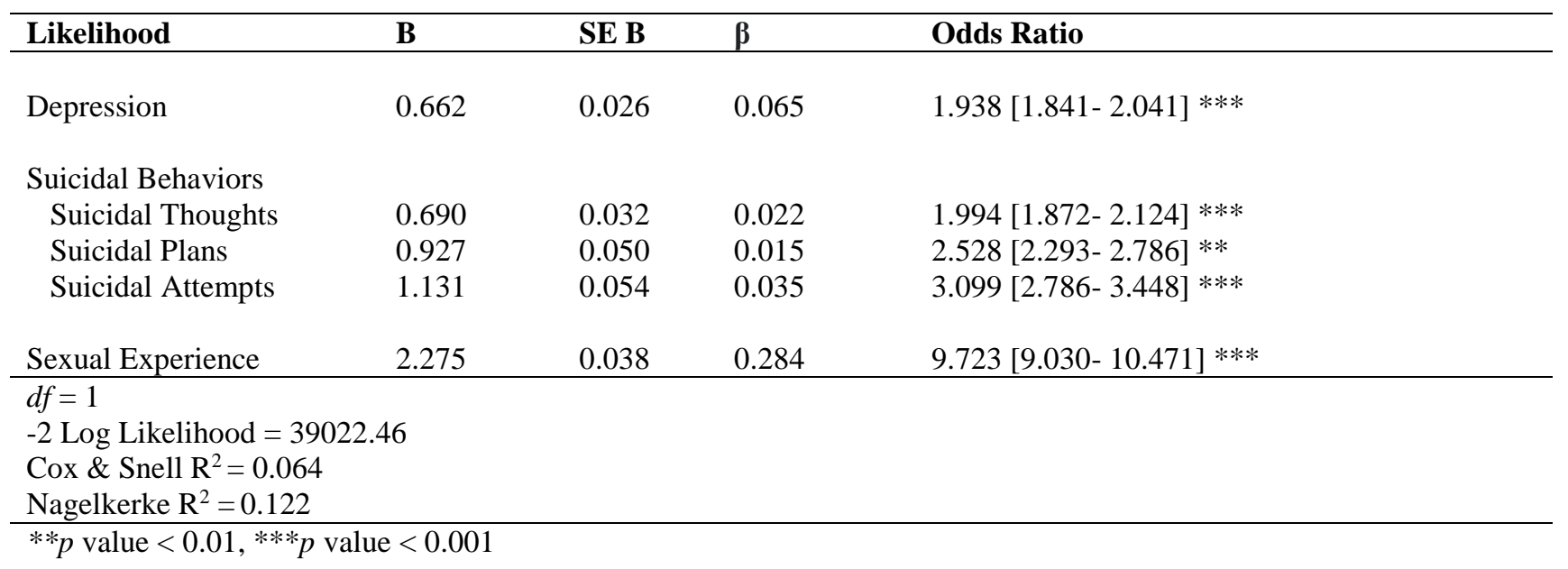

\section{DISCUSSION}

This study highlighted the clinical importance of considering sexual experience, depression, and suicidal behaviors, as notably correlated and may instigate smoking and drinking. This research had obtained vital strength based on the model generated from a large national representative sample (KYRBS), descriptive characteristics and demographic factors that could determine correlations and probabilities. The overall outcome indicated that all the study variables showed significant evidence on the association and maximum likelihood in substance usage development and did not provide any adverse findings in all the results. This means that the empirical outcome supported and answered our questions about whether there were associations and likelihood among Korean students with sexual experiences, mental health problems, and suicidal impulses to smoke and drink.

The most notable finding in the present study underscored sexual experience, which exhibited consistency in the overall results. Previous investigations may have explained that this must be due to adolescence's frequent characterizations as consistent with rebelliousness and sexual experience [37]. Pubescent is a stage of self-discovery, curiosity, and experimentation. In this context, teenage sexual development and sexual behavior occur and may place adolescents at higher risk for undesired consequences such as drinking, smoking, and suicide [38]. Prior studies have also shown similar reports that were consistent with our findings-indicative that adolescent sexual experience had association and tendencies to influence smoking and drinking initiation. The results of the current investigation were also substantiated by the foregoing reports that these factors could also predict usage, especially when there is a history of childhood domestic violence, such as experiencing physical and sexual abuse. Though these acts may be concealed, it must be a powerful reason adolescents initiate substance use [39-42]. Sexual experience may affect an individual's drinking behavior starting at an early stage in life [41]. Higher levels of both sexual-based alcohol expectancies (i.e., interpersonal closeness, sexual pleasure, sexual opportunities, sexual disinhibition) and drinking motives may turn sexually active students more susceptible to more habitual intoxication and heavier drinking episodes [39, 43-44].

Findings on depression revealed a pertinently high correlation with alcohol, but the probability was higher with smoking. Empirical evidence from prior studies supported the finding that depression demonstrated causative smoking initiation by increasing initiation risk. Further, it demonstrated causative smoking initiation by intensifying progression to regular use, increasing the risk of chronic smoking, reducing the potentiality for smoking cessation, and providing a distinctive background for theorizing psychological smoking maintenance mechanisms among depressed smokers [4547]. Increased depression symptoms could relatively influence more psychiatric severe symptoms on alcohol initiation and an increased risk for heavy drinking episodes [48-49]. Adequately, previous studies had also heightened the strength of the current investigation on depression as not only associatively but also commonly and equivalently strong predictors for smoking and alcohol initiation [31, 50-51]. Establishing a clear connection between suicidal behaviors and substance use behaviors has dramatically been a challenge for the academic community. Nonetheless, scholars have sought to explain why, when, or how the two are correlated. Currently, little is known about the longitudinal relationships between suicidal behaviors to later substance use, and minimal explanations exist concerning their ambiguous relationship. 
In numerous published findings, the cohesion was that they treat suicide as the outcome variable and regard smoking as the core predictor [51]. However, this is not the case in the present study. This study reversed the analytical direction by examining the level to which sexual experience, depression, and suicidal behaviors, may play a part in the odds of smoking and alcohol drinking. Further results indicated that suicidal behaviors were less associated with substance consumption but had a greater likelihood for alcohol and drinking compulsions. The current study's exposition was coherent with the previous findings, having observed an indicatively stronger connection with increased mental health problems on depression [47, 52-53], suicidal behaviors [54-57], and sexual experience [29, 36, 39, 41-42] as substantively associated with increased substance use. Despite contradiction from three longitudinal studies, this investigation strongly argued that suicide was contemporaneous with smoking and drinking and considered initiation factors. Adolescents suffering from suicidal impulses varying from thoughts and attempts to relapse and completion can shape individual smoking behavior directly or interactively [52, 58-60].

\section{LIMITATION OF THE STUDY}

The most apparent limitation of the present study was its cross-sectional design. Causality and directionality between sexual experience, mental health problems and substance use could not be specified. Although the data used were accepted as a reliable source of information concerning teenage delinquent behaviors, but solely due to its nature of self-report-based measures we could only determine predictability in the likelihood and not the causality. Another possible limitation of the study was the respondents may have biases and may have not answered truthfully particularly with the sensitive questions. Furthermore, we could not apply exact measures for mental health problems in adolescents based only on experience, as described in this study. Diagnostic criteria to assess the mental health problems was not performed and the lack of pertinent information from other sources like the parents were not included. However, despite these limitations, this study presented an important contribution to the literature in the fields of risky sexual experience, mental health problems and its association and effect to substance use motivation.

\section{CONCLUSION AND RECOMMENDATION}

Knowledge gained from this prospective cross-sectional study implies that increased sexual experience, suicidal behaviors and depression are significant risk factors for developing substance use behaviors among adolescents. Sexual experience should not be treated any less considering the fact that teenagers are highly experimental and do not seem to be aware of the perilous consequences. It should also be noted that as the risk factors were augmented substance use would also be boosted. If these medical conditions are not adequately addressed, a severe functional impairment may intensify the complication. It may likely progress into co-occurring disorders in which substance use may double the impact for the risk factors, and vice versa. This condition might affect and prolong treatment due to relapse tendencies with the substance usage. For efficient and effective management of sexual experience, suicidal behaviors and depression on teenagers, findings underscore the need for early detection on adolescents at risk. A comprehensive prevention and protective efforts are required along with continuous parental guidance. Intervention programs with coping skills to handle emotional and behavioral problems is essential to help reduce the probability of an increased risk factors and subsequently lessen the threat for developing cigarette smoking and alcohol drinking behaviors among teenagers. Schoolbased programs that can create synergy by embedding teenagers in an academic environment that is equally supportive, beneficial and can help promote a positive mindset is recommended. Future prospective research should aim to understand the extent as how and when these relationships occur among adolescence and how the impact would affect them.

\section{REFERENCES}

[1] Schorling, J. B., Gutgesell, M., Klas, P., Smith, D., Keller, A. "Tobacco, alcohol and other drug use among college students", Journal of substance abuse, vol. 6 no.1 pp. 105-115, 1994.

[2] Bauman, A., Phongsavan, P., Cousijn., Luijten., Ewing., "Epidemiology of substance use in adolescence: prevalence, trends and policy implications", Drug and Alcohol Dependence, vol. 55 no. 3, 187-207, 1999, 2018

[3] Das, J. K., Salam, R. A., Arshad, A., Finkelstein, Y., Bhutta, Z. A., "Interventions for adolescent substance abuse: An overview of systematic reviews". Journal of Adolescent Health, vol. 59, no. 4, pp. 61-75, 2016.

[4] Ritchie, H., Roser, M. "Sanitation." Our World in data 2019.

[5] Tomás-Rosselló, J., Rawson, R. A., Zarza, M. J., Bellows, A., Busse, A., Saenz, E., Ling, W., “Treatment Substance Abuse", United Nations office on drugs and international crime network of drug dependence treatment and rehabilitation resource centers, vol. 31 no. 4, pp. 251-263, 2010

[6] Kanyoni, M., Gishoma, D., Ndahindwa, V. "Prevalence of psychoactive substance use among youth in Rwanda", BMC research notes, vol.8 pp. 1, pp. 1-8, 2015

[7] Reports about Suicide No. 1 cause of death for S. Korean teens, youths. Korean Herald; [accessed on 26 April 2018 ]. 
Available at http://www.koreaherald.com/view.php?ud=20180426000581.

[8] Reports about Forecast of the smoking prevalence in South Korea from 2010 to 2025. Statistica; [accessed on 20 July 2021]. Available at http://www.statista.com/forecasts/1148772/smoking-prevalence-forecast-in-south-korea.

[9] Rappeneau, Virginie, Anne Bérod, "Reconsidering depression as a risk factor for substance use disorder: Insights from rodent models." Neuroscience \& Biobehavioral Reviews vol. 77, pp. 303-316, 2017

[10] Reports on Alcohol and Drug Foundation. Australian Drug Foundation; [accessed on 13 August 2021]. Available at https://idpc.net/profile/australian-drug-foundation-adf.

[11] Kuria, Mary W., David M. Ndetei, Isodore S. Obot, Lincoln I. Khasakhala, Betty M. Bagaka, Margaret N. Mbugua, Judy Kamau, "The association between alcohol dependence and depression before and after treatment for alcohol dependence", International Scholarly Research Notices, 2012

[12] Poulin, C., Hand, D., Boudreau, B., Santor, D., "Gender differences in the association between substance use and elevated depressive symptoms in a general adolescent population", Addiction, vol. 100, no. 4, pp. 525-535, 2005

[13] Carmo, D. R. P. D., Siqueira, D. F. D., Mello, A. D. L., Freitas, E. D. O., Terra, M. G., Cattani, A. N., Pillon, S. C., "Relationships between substance use, anxiety, depression, and stress by public university workers", Revista Brasileira de Enfermagem, 73, 2020

[14] Danielson, C. K., Overholser, J. C., Butt, Z. A., “Association of substance abuse and depression among adolescent psychiatric inpatients", The Canadian Journal of Psychiatry, vol. 48 no. 11, pp. 762-765, 2003

[15] Chang, H. B., Munroe, S., Gray, K., Porta, G., Douaihy, A., Marsland, A., Melhem, N. M. “The role of substance use, smoking, and inflammation in risk for suicidal behavior". Journal of affective disorders, vol. 243, pp.33-41, 2019

[16] Jeon, H. S. "Effects of smoking, drinking, and drug use on the adolescent's suicidal ideation using the data of the Korea youth risk behavior through web-based survey from 2008 to 2014", Journal of the Korean Society of School Health, vol. 28 no. 2, pp. 99-110, 2015

[17] Han, M. A., Kim, K. S., Ryu, S. Y., Kang, M. G., Park, J., “Associations between smoking and alcohol drinking and suicidal behavior in Korean adolescents: Korea Youth Behavioral Risk Factor Surveillance 2006”, Preventive [1]

[18] Poorolajal, J., Darvishi, N., "Smoking and suicide: a meta-analysis". PloS one, vol. 11, no. 7, e0156348, 2016

[19] Hunt, G. E., Malhi, G. S., Lai, H. M. X., Cleary, M., "Prevalence of comorbid substance use in major depressive disorder in the community and clinical settings, 1990-2019: systematic review and meta-analysis", Journal of affective disorders, vol. 266, pp. 288-304 2020

[20] Vincke, E., "Female cigarette and alcohol consumption as a short-term mating strategy", Evolutionary Psychology 14, no. 4, 1474704916681300, 2016

[21] Farid, N. D. N., Che'Rus, S., Dahlui, M., Al-Sadat, N., \& Aziz, N. A., "Predictors of sexual risk behavior among adolescents from welfare institutions in Malaysia: a cross-sectional study", BioMed Central, In BMC public health Vol. 14, No. 3, pp. 1-8, 2014

[22] Kim, S. J., \& Cho, K. W., "Interaction between smoking cigarettes and alcohol consumption on sexual experience in high school students", Osong public health and research perspectives, vol. 10, no. 5, pp. 274, 2019

[23] Vincke, E., "The young male cigarette and alcohol syndrome: Smoking and drinking as a short-term mating strategy", Evolutionary Psychology, vol. 14, no. 1, 1474704916631615, 2016

[24] Cavazos-Rehg, P. A., Krauss, M. J., Spitznagel, E. L., Schootman, M., Cottler, L. B., Bierut, L. J., "Number of sexual partners and associations with initiation and intensity of substance use", AIDS and Behavior, vol.15, no. 4, pp. 869-874, 2011

[25] Ritchwood, T. D., Ford, H., DeCoster, J., Sutton, M., \& Lochman, J. E., "Risky sexual behavior and substance use among adolescents: A meta-analysis," Children and youth services review", vol. 52, pp.74-88, 2015

[26] Viana, T. B. P., Camargo, C. L., Gomes, N. P., Felzemburgh, R. D. M., Mota, R. S., Lima, C. C. O. J., "Factors associated with cigarette smoking among public school adolescents", Rev Esc Enferm USP, vol. 52, e03320, 2018

[27] Reports on Reporting guidelines reduced number of suicides: study. Korean Herald; [accessed on 25 July 2021 ]. Available at http://www.koreaherald.com/view.php?ud=20180426000581.

[28] Reports on Brands of cigarettes ranked by number of users in Great Britain from 2018 to 2020. Statistica; [accessed on 23 July 2021]. Available at https://www.statista.com/forecasts/1148772/smoking-prevalence-forecast-in-south-korea.

[29] Lim, D., Ha, M., Song, I., "Trends in the leading causes of death in Korea, 1983-2012", Journal of Korean medical science, vol. 29, no. 12, pp. 1597-1603, 2014

[30] Hong, C. H., "Current health issues in Korean adolescents”, Korean journal of pediatrics, vol. 54, no.10, 395, 2011

[31] Park, B., Park, B., Han, H., Choi, E. J., Kim, N. E., Shin, Y., Park, H., "Projection of the Years of Life Lost, Years Lived with Disability, and Disability-Adjusted Life Years in Korea for 2030", Journal of Korean medical science, 34(Suppl 1), 2019.

[32] Jeon, H. S., "Effects of smoking, drinking and drug use on the adolescent's suicidal ideation by using the data of the Korea youth risk behavior web-based survey through from 2008 to 2014", Journal of the Korean Society of School Health, vol. 28, no. 2, pp. 99-110, 2015

[33] Singh, A., "The Scourge of South Korea: Stress and suicide in Korean society”, Berkeley Political Review 23, 2017 
[34] Trends in percentage of Korean adolescents who experienced depression, 2007-2018/ http://www.kdca.go.kr/board/board.es?mid=a30501000000\&bid=0031\&list_no=143514\&act=view\# http://www.cdc.go.kr/yhs

[35] Gunter, Rebekah, Edwin Szeto, Se-Hoon Jeong, Sooyeon Aly Suh, and Andrew J. Waters., "Cigarette smoking in South Korea: a narrative review", Korean journal of family medicine, vol. 41, no. 1, :3, 2020

[36] Lee, G. Y., Choi, Y. J., “Analysis of Korean adolescents' sexual experience and substance use: Social Behavior and Personality”, an international journal, vol. 45, no. 5, pp. 809-817, 2017

[37] Clayton, S., Young people today actively expressed their sexual curiosity and interest in sex, and more inclined and open, they tend toward it, 1991/ Daehee Lee, Jonghwa Lee, “The Relationship between Youth's View of Sexual Experience and Temperament and Its Impact on Crime," Autonomous Police Research, Vol. 4, No. 1, pp.228-261, 2011.

[38] Best, C., Fortenberry, J. D., “Adolescent sexuality and sexual behavior”, In Handbook of adolescent health psychology, pp. 271-291, Springer, New York, NY, 2013 /Yunjeong Bu, Moonjeong Kang, Jiseon Lee, "Factors Related to the Biblical Experience of Youth," Journal of the Korean School Health Association, Vol. 30, No. 2, pp.154-163, 2017

[39] Sussman, S., "Relations of cigarette smoking with risky sexual behavior among teens", Sexual Addiction \& Compulsivity, vol. 12 no. 2-3, 1pp. 81-199, 2005

[40] Kristman-Valente, A. N., Brown, E. C., Herrenkohl, T. I, "Child physical and sexual abuse and cigarette smoking in adolescence and adulthood", Journal of Adolescent Health, vol. 53, no. 4, pp. 533-538, 2013

[41] LaBrie, J. W., Kenney, S. R., Migliuri, S., Lac, A., "Sexual experience and risky alcohol consumption among incoming first-year college females", Journal of child \& adolescent substance abuse, vol. 20, no. 1, pp. 15-33. 2010

[42] Han, M. A., Kim, K. S., Ryu, S. Y., Kang, M. G., Park, J., “Associations between smoking and alcohol drinking and suicidal behavior in Korean adolescents: Korea Youth Behavioral Risk Factor Surveillance, 2006 ”, Preventive medicine, vol. 49, no. 23, pp. 248-252, 2009

[43] De Von Figueroa-Moseley, C., Landrine, H., Klonoff, E. A., "Sexual abuse and smoking among college student women", Addictive Behaviors, vol. 29, no. 2, pp. 245-251, 2004

[44] Breslau, N., Peterson, E. L., Schultz, L. R., Chilcoat, H. D., Andreski, P., "Major depression and stages of smoking: a longitudinal investigation", Archives of general psychiatry, vol. 55, no. 2, pp. 161-166, 1998

[45] Kendler, K. S., Neale, M. C., MacLean, C. J., Heath, A.C., Eaves, L. J., Kessler, R. C., "Smoking and major depression: a causal analysis", Arch Gen Psychiatry, 5036- 43 Google Scholar, 1993/ Hughes, JR. Clonidine., “depression, and smoking cessation”, JAMA. 2592901- 2902 Google Scholar.

[46] Rappeneau, V., \& Bérod, A., "Reconsidering depression as a risk factor for substance use disorder: Insights from rodent models", Neuroscience \& Biobehavioral Reviews, 77, 303-316, 2017

[47] Hartka, E., Johnstone, B., Leino, E. V., Motoyoshi, M., Temple, M. T., Fillmore, K. M., “A meta-analysis of depressive symptomatology and alcohol consumption over time”, British journal of addiction, vol. 86, no. 10, pp. 1283-1298, 1991

[48] Crum, R. M., Storr, C. L., Ialongo, N., Anthony, J. C., "Is depressed mood in childhood associated with an increased risk for initiation of alcohol use during early adolescence?", Addictive behaviors, vol. 33, no. 1, pp. 24-40, 2008

[49] Wu, P., Bird, H. R., Liu, X., Fan, B., Fuller, C., Shen, S., Canino, G. J., "Childhood depressive symptoms and early onset of alcohol use", Pediatrics, vol. 118, no. 5, pp. 1907-1915, 2006

[50] Maughan, B., Collishaw, S., Stringaris, A., "Depression in childhood and adolescence", Journal of the Canadian Academy of Child and Adolescent Psychiatry, vol. 22, no.1, pp. 35, 2013

[51] Gonzalez, V. M., Bradizza, C. M., Collins, R. L., “, Drinking to cope as a statistical mediator in the relationship between suicidal ideation and alcohol outcomes among underage college drinkers", Psychology of Addictive Behaviors, vol.23, no. 3, pp. 443, 2009

[52] Breslau, N., Peterson, E. L., Schultz, L. R., Chilcoat, H. D., Andreski, P., "Major depression and stages of smoking: a longitudinal investigation", Archives of general psychiatry, vol. 55, no. 2, pp. 161-166, 1998

[53] Brynner J.M., “The Young Smoker”, London, England: Her Majesty’s Stationery Office; 1969. Kandel, DB., Davies, M., "Adult sequelae of adolescent depressive symptoms”, Arch Gen Psychiatry. 43255- 262, 1986

[54] Han, M. A., Kim, K. S., Ryu, S. Y., Kang, M. G., Park, J., “Associations between smoking and alcohol drinking and suicidal behavior in Korean adolescents: Korea Youth Behavioral Risk Factor Surveillance”, Preventive medicine, vol. 49, no. 2-3, pp. 248-252, 2006

[55] Kim, H. H. S., Kim, H. J., \& Kim, E. M., "Exploring the Association between Suicidality and Smoking Behavior among School-Based Children in Lao People's Democratic Republic (PDR)”, Journal of psychoactive drugs, vol. 52, no. 1 , pp. $46-55,2020$

[56] Byeon, K. H., Jee, S. H., Sull, J. W., Choi, B. Y., Kimm, H., "Relationship between binge drinking experience and suicide attempts in Korean adolescents: based on the 2013 Korean Youth Risk Behavior Web-based Survey", Epidemiology and health, 40, 2018

[57] Dawes, M. A., Mathias, C. W., Richard, D. M., Hill-Kapturczak, N., Dougherty, D. M., “Adolescent suicidal 
behavior and substance use: developmental mechanisms", Substance abuse: research and treatment, 2, SART-S1044, 2008

[58] Bagge, C. L., \& Sher, K. J., “Adolescent alcohol involvement and suicide attempts: Toward the development of a conceptual framework", Clinical Psychology Review, vol. 28, no. 8, pp. 1283-1296, 2008

[59] Spokas, M., Wenzel, A., Brown, G. K., Beck, A. T., "Characteristics of individuals who make impulsive suicide attempt", Journal of affective disorders, vol. 136, no. 3, pp. 1121-1125, 115, 2012 / Sussman, S., "Relations of cigarette smoking with risky sexual behavior among teens", Sexual Addiction \& Compulsivity, vol. 12, no. 2-3, pp. 181-199, 2005

[60] Fergusson, D. M., Boden, J. M., Horwood, L. J., "Structural models of the comorbidity of internalizing disorders and substance use disorders in a longitudinal birth cohort", Soc Psychiatry Psychiatry Epidemiol, 46:933-942. [PubMed] [Google Scholar], 2011 